\title{
Pulmonary Complications following Major Lung Resection for Benign and Malignant Lung Diseases
}

\author{
Adel K. Ayed ${ }^{\mathrm{a}, \mathrm{b}}$ Samer Bazerbashi $^{\mathrm{b}}$ Chezhian Chandrasekaran $^{\mathrm{b}}$ \\ Murugan Sukumar ${ }^{\mathrm{b}}$ Hassan Jamaleddin ${ }^{\mathrm{b}}$ \\ ${ }^{a}$ Department of Surgery, Faculty of Medicine, Kuwait University and ${ }^{\mathrm{b}}$ Department of Thoracic Surgery, \\ Chest Diseases Hospital, Kuwait
}

\section{Key Words}

Pulmonary complications • Pulmonary function test • Lobectomy

\begin{abstract}
Objective: To assess the incidence and to identify the possible associated risk factors for postoperative pulmonary complications after major lung resection. Subjects and Methods: One hundred and sixty-eight consecutive patients undergoing major lung resection for benign and malignant lung disease over a 3-year period were included in the study. Preoperative assessment clinical parameters, intraoperative and postoperative events were recorded. Pulmonary complications were noted according to a precise definition. The risk of complications associated with age, comorbidity, forced vital capacity (FVC), blood transfusion and extended operation was evaluated using logistic regression analysis. Results: The mean age of the patients was 47.1 years (range 1680 years), 137 (77\%) patients underwent lobectomy, 23 (14\%) pneumonectomy, and 15 (9\%) bilobectomy. Fortysix $(27 \%)$ patients developed postoperative pulmonary complications and $2(1.1 \%)$ died within 30 days following the operation. Age $\geq 65$ years (OR 3.7, 95\% Cl: 1.5-8.6, $p=0.002$ ), the presence of comorbid cardiopulmonary
\end{abstract}

disease (OR 0.2, 95\% Cl: $0.1-0.5, \mathrm{p}=0.001$ ), FVC $<50 \%$ (OR $0.2,95 \% \mathrm{Cl}: 0.1-0.8, \mathrm{p}=0.02$ ), blood transfusion (OR $0.2,95 \% \mathrm{Cl}: 0.1-0.4, \mathrm{p}=0.0001$ ), and extended operation (OR $0.2,95 \% \mathrm{Cl}: 0.07-0.6, \mathrm{p}=0.005$ ) were the identified factors associated with the development of postoperative pulmonary complications, which necessitated an increased length of hospital stay. Conclusion: Postoperative pulmonary complications are more likely to develop in patients with age $\geq 65$ years with comorbid cardiopulmonary disease, FVC $<50 \%$, blood transfusion, and extended operation.

Copyright $(2006$ S. Karger AG, Basel

\section{Introduction}

Major lung resection belongs to the group of surgical procedures with significant morbidity. Despite advances in surgical techniques and perioperative care, mortality ranges from 2 to $12 \%[1,2]$. Significant respiratory impairment is caused by parenchymal resection and deterioration of ventilatory mechanics. In addition, a wide spectrum of postoperative pulmonary complications (PPCs) may occur in as much as 30-60\% of patients [3]. Therefore, improvement of patients' survival and quality of life following major lung resection can be achieved

\section{KARGER}

Fax +4161306 1234 E-Mail karger@karger.ch www.karger.com
(C) 2006 S. Karger AG, Basel

1011-7571/06/0152-0114\$23.50/0

Accessible online at:

www.karger.com/mpp
Dr. Adel Khader Ayed

Department of Surgery, Faculty of Medicine

Kuwait University, PO Box 24923

13110 Safat (Kuwait)

Tel. +965 531 9475, Fax +965531 9579, E-Mail Adel@hsc.edu.kw 
through identification of operative risk factors and highquality perioperative medical care. However, there have been relatively few prospective studies accurately describing the PPCs that may occur following major lung resection.

The objectives of this study were to describe the PPCs after major pulmonary resection, and assess the preoperative or intraoperative factors that may predispose to the development of these PPCs.

\section{Subjects and Methods}

\section{Selection of Patients}

From January 2002 to December 2004, 168 patients (119 male and 49 female; mean age 47.1 years, range $16-80$ years) who underwent major pulmonary resection, lobectomies, bilobectomies (removal of two lobes in the right side) or pneumonectomies (removal of whole lung) were included in this study. Patients who underwent wedge resections, exploratory or staging thoracotomy procedures, thoracoscopy with wedge excisions of the lung and emergency lung resections were excluded from the study. All patients were operated on by the same surgical team through either a standard posterolateral thoracotomy $(\mathrm{n}=110)$ or muscle-sparing thoracotomy $(n=58)$. Extended resections were performed in 20 patients and that included 13 chest wall, 4 pericardial and 3 diaphragmatic resections. All surgical procedures were performed under general anaesthesia with a double-lumen endotracheal tube. Unless otherwise indicated, all patients were extubated in the operating room at the end of the operation and transferred to a monitored thoracic ward bed. Postoperative pain control was mainly achieved by epidural analgesia. All patients had an active program of chest physiotherapy and incentive spirometry during the postoperative period.

\section{Data Collection}

Preoperative assessment included the documentation of historic information (comorbid diseases) as well as preoperative haemoglobin, serum creatinine, and serum albumin. Associated comorbidity factors were defined as coronary artery disease (angina or myocardial infarction), congestive heart failure, peripheral vascular disease, chronic obstructive airway disease, chronic renal failure and diabetes mellitus. Preoperative pulmonary evaluation included arterial blood gas analysis $\left(\mathrm{Pa} \mathrm{CO}_{2}, \mathrm{~Pa} \mathrm{O}_{2}\right)$ and spirometry, forced expiratory volume in $1 \mathrm{~s}$ (FEV1) expressed in percent with regard to theoretical FEV1, and forced vital capacity (FVC) expressed in percent with regard to theoretical FVC.

\section{Postoperative Evaluation}

All patients were followed up after surgery and complications occurring during hospitalization were recorded. Complications were defined to include pulmonary complications: pneumonia (fever $>38^{\circ} \mathrm{C}$, purulent sputum, new and persistent lung infiltrate on chest radiograph), atelectasis evidenced on chest radiograph requiring bronchoscopy, prolonged air leak (duration of chest tube drainage $>7$ days), postlobectomy space, bronchopleural fistula, empyema, adult respiratory distress syndrome, acute respiratory failure (postoperative ventilator dependence $>24 \mathrm{~h}$ or reintubation for controlled ventilation), pneumothorax evidenced on chest radiograph requiring chest tube placement and bleeding.

\section{Statistical Analysis}

Data were expressed as mean, number or percentages. Data analyses were made using SPSS software for Windows ${ }^{\circledR}$ version 8 packages (SPSS, Chicago, Ill., USA). The cutoff level for statistical significance was $\mathrm{p}<0.05$. The unpaired Student $t$ test was used to assess the significance between means of continuous variables in two groups. The Pearson $\chi^{2}$ test was used to ascertain the significance of association between the two categorical variables. The $\chi^{2}$ test was replaced by Fisher's exact test if the cell frequencies of the $2 \times 2$ contingency table dropped below 5. Multivariate analysis was used to identify predictors for the development of postoperative respiratory complications.

\section{Results}

\section{Study Population}

Of the 168 patients, pulmonary resection was indicated for non-small cell lung cancer in $94(56 \%)$ cases and benign lung disease in $74(44 \%)$ cases. The aetiology of benign lung disease included bronchiectasis in 40 patients, tuberculosis sequelae in 11 , lung abscess in 9 , fungus ball in 7 and organizing pneumonia in 7. Lobectomy, the most common operation, was performed in $130(77 \%)$ cases, while 23 (14\%) patients underwent pneumonectomy and 15 (9\%) bilobectomy. Eighty-two (48.8\%) patients had a comorbid disease, such as hypertension, diabetes mellitus and chronic obstructive airway disease. The clinical data of patients with benign and malignant lung diseases are shown in table 1.

\section{Postoperative Pulmonary Complications}

Forty-six (27\%) patients developed a total of 53 PPCs (table 2). There was no significant difference between the pulmonary complication rate and the operative procedure. Six (26\%) PPCs occurred after pneumonectomies, 35 (27\%) after lobectomies, and 5 (33\%) after bilobectomies $(\mathrm{p}=0.8)$. Prolonged air leak $(15 \%)$ and atelectasis $(4 \%)$ were the most prevalent complications, followed by bronchopleural fistula (3\%), and bacterial pneumonia (2.4\%). Air leak occurred in 13 of 74 (17.5\%) patients in whom pulmonary resection was done for benign disease, and in 12 of $94(12.7 \%)$ patients with malignant disease. The difference was statistically not significant $(\mathrm{p}=0.2)$. Prolonged air leak occurred in $20(15.4 \%)$ and $5(33.3 \%)$ patients for whom lobectomy and bilobectomy were done, respectively. The difference was statistically significant $(\mathrm{p}=0.01)$.

Thirteen (8\%) patients experienced 15 complications other than respiratory ones, including 8 cardiovascular 
Table 1. Characteristics of patients with benign and malignant lung diseases

\begin{tabular}{|c|c|c|c|c|c|}
\hline & $\begin{array}{l}\text { Benign } \\
\text { lung disease } \\
(n=74)\end{array}$ & $\begin{array}{l}\text { Malignant } \\
\text { lung disease } \\
(\mathrm{n}=94)\end{array}$ & OR & $95 \% \mathrm{CI}$ & $\mathrm{p}$ value \\
\hline $\mathrm{Age}^{\mathrm{a}}$, years & $40.24(14)$ & $52.6(12.9)$ & - & $8.2-16.5$ & 0.0001 \\
\hline Sex $(M: F)$ & $40: 34$ & $79: 15$ & 4.4 & $2.1-9.1$ & 0.0001 \\
\hline Smoking (Y:N) & $25: 49$ & $81: 13$ & 12.2 & $5.7-26$ & 0.0001 \\
\hline Comorbid cardiopulmonary disease $(\mathrm{Y}: \mathrm{N})$ & $31: 43$ & $51: 43$ & 1.6 & $0.8-3$ & 0.07 \\
\hline FVC $(<50 \%: \geq 50 \%)$ & $8: 66$ & $9: 85$ & 0.8 & $0.3-2.3$ & 0.7 \\
\hline FEV1 $(<1.3$ litres: $\geq 1.3$ litres $)$ & $8: 66$ & $8: 86$ & 0.7 & $0.2-2.1$ & 0.6 \\
\hline Haemoglobin $(\leq 10 \mathrm{~g} / \mathrm{dl}:>10 \mathrm{~g} / \mathrm{dl})$ & $18: 56$ & $11: 83$ & 0.4 & $0.1-0.9$ & 0.02 \\
\hline Serum albumin ${ }^{\mathrm{a}}, \mathrm{g} / \mathrm{dl}$ & $34(8.2)$ & $33.5(6.6)$ & - & -2.7 to 1.7 & 0.6 \\
\hline Side (right:left) & $40: 34$ & $53: 41$ & 0.7 & $0.5-2$ & 0.6 \\
\hline Transfusion $(\mathrm{Y}: \mathrm{N})$ & $35: 39$ & $25: 69$ & 0.4 & $0.2-0.7$ & 0.004 \\
\hline Hypertension (Y:N) & $8: 66$ & $7: 87$ & 0.6 & $0.2-1.9$ & 0.4 \\
\hline Diabetes mellitus (Y:N) & $3: 71$ & $13: 81$ & 3.7 & $1-13$ & 0.03 \\
\hline Ischaemic heart disease (Y:N) & $2: 72$ & $9: 85$ & 3.8 & $0.7-18$ & 0.07 \\
\hline Respiratory disease $(\mathrm{Y}: \mathrm{N})$ & $12: 62$ & $15: 79$ & 0.9 & $0.4-2.2$ & 0.9 \\
\hline Lobectomy, bilobectomy vs. pneumonectomy & $72: 2$ & $73: 21$ & 0.09 & $0.02-0.4$ & 0.0001 \\
\hline Muscle sparing vs. standard thoracotomy & $31: 43$ & $27: 67$ & 0.5 & $0.2-1$ & 0.07 \\
\hline Postoperative complications (Y:N) & 29:45 & $30: 64$ & 0.7 & $0.3-1.3$ & 0.2 \\
\hline Operating time $\mathrm{a}^{\mathrm{a}} \mathrm{h}$ & $3.5(0.8)$ & $2.9(0.6)$ & - & -0.7 to 0.3 & 0.02 \\
\hline Intraoperative blood loss ${ }^{\mathrm{a}}, \mathrm{ml}$ & $492.4(348.3)$ & $329.1(271.4)$ & - & -25 to 68.8 & 0.001 \\
\hline Extended operation (Y:N) & $3: 71$ & $17: 77$ & 5.2 & $1.4-18$ & 0.005 \\
\hline
\end{tabular}

$\mathrm{OR}=$ Odds ratio; $\mathrm{CI}=$ confidence interval $; \mathrm{Y}=$ yes $; \mathrm{N}=$ no.

${ }^{a}$ Mean (SD).

ones (6 arrhythmias and 2 myocardial infarctions), 4 genitourinary ( 2 acute renal failures and 2 urinary retentions), and 3 miscellaneous ( 2 wound infections and 1 hypernatraemia).

\section{Risk Factors for PPCs}

Perioperative data for patients with or without pulmonary complications are presented in table 3 . In univariate analysis, age, associated comorbid cardiopulmonary conditions, FEV1, FVC, haemoglobin $\leq 10 \mathrm{mg} / \mathrm{dl}$, operation side, preoperative/intraoperative blood transfusion, extended resection and intraoperative blood loss were associated significantly with postoperative pulmonary complications. Preoperative FEV1 and FVC were predictive of pulmonary complications. Pulmonary complications occurred in 10 of $16(62.5 \%)$ patients with FEV1 $<1.3$ litres versus 36 of 152 (24\%) patients with FEV1 >1.3 litres $(p=0.002)$. Stepwise logistic regression analysis of perioperative variables independently associated with PPCs is given in table 4. Five risk factors were associated with the development of PPCs: age $\geq 65$ years, presence of comorbid cardiopulmonary disease, FVC
Table 2. Pulmonary complications in 168 patients

\begin{tabular}{lcc}
\hline Complications & Number & $\%$ \\
\hline Prolonged air leak & 25 & 15 \\
Atelectasis & 7 & 4.2 \\
Bronchopleural fistula & 5 & 3 \\
Bacterial pneumonia & 4 & 2.4 \\
Mechanical ventilation & 3 & 1.8 \\
Respiratory insufficiency & 3 & 1.8 \\
Haemothorax & 2 & 1.2 \\
Pneumothorax & 2 & 1.2 \\
Residual pleural space & 2 & 1.2 \\
\hline Total & 53 & 31.8 \\
\hline
\end{tabular}

$<50 \%$, blood transfusion and extended operation. Two independent risk factors were associated with the development of prolonged air leak: extended operation (OR 8.8, 95\% CI: 3.1-24.7, $\mathrm{p}=0.0001)$ and patients with chronic obstructive airway disease (OR 3.8, 95\% CI: $1.3-11.2, \mathrm{p}=0.01)$. 
Table 3. Characteristics of patients with or without pulmonary complications, univariate analysis

\begin{tabular}{|c|c|c|c|c|c|}
\hline & $\begin{array}{l}\text { With pulmonary } \\
\text { complications } \\
(\mathrm{n}=46)\end{array}$ & $\begin{array}{l}\text { Without pulmonary } \\
\text { complications } \\
(\mathrm{n}=122)\end{array}$ & OR & $95 \% \mathrm{CI}$ & $\mathrm{p}$ value \\
\hline Age ( $<65$ years: $\geq 65$ years $)$ & $20: 26$ & $98: 24$ & 0.3 & $0.15-0.66$ & 0.002 \\
\hline Sex $(M: F)$ & $36: 10$ & $83: 39$ & 1.6 & $0.76-3.7$ & 0.1 \\
\hline Smoking (Y:N) & $30: 16$ & $76: 46$ & 1.1 & $0.5-2.3$ & 0.4 \\
\hline Comorbid cardiopulmonary disease $(\mathrm{Y}: \mathrm{N})$ & $33: 13$ & $49: 73$ & 3.7 & $1.8-7.9$ & $<0.0001$ \\
\hline FVC $(<50 \%: \geq 50 \%)$ & $11: 35$ & $6: 116$ & 6.1 & $2.1-17.6$ & 0.001 \\
\hline FEV1 (<1.3 litres: $\geq 1.3$ litres $)$ & $10: 36$ & $6: 116$ & 5.3 & $1.8-15.7$ & 0.002 \\
\hline Haemoglobin $(\leq 10 \mathrm{~g} / \mathrm{dl}:>10 \mathrm{~g} / \mathrm{dl})$ & $17: 29$ & $12: 110$ & 5.3 & $2.3-12.5$ & $<0.0001$ \\
\hline Serum albumin ${ }^{\mathrm{a}}, \mathrm{g} / \mathrm{dl}$ & $28.7(5.2)$ & $36.4(6.9)$ & - & $5.7-9.8$ & 0.2 \\
\hline Side (right:left) & $32: 14$ & $61: 61$ & 2.2 & $1.1-4.7$ & 0.01 \\
\hline Transfusion $(\mathrm{Y}: \mathrm{N})$ & $28: 18$ & $32: 90$ & 4.3 & $2.1-8.9$ & $<0.0001$ \\
\hline Hypertension (Y:N) & $7: 39$ & $8: 114$ & 2.5 & $0.8-7.5$ & 0.07 \\
\hline Diabetes mellitus (Y:N) & $7: 39$ & $9: 113$ & 2.5 & $0.7-6.4$ & 0.1 \\
\hline Ischaemic heart disease (Y:N) & $1: 45$ & $10: 112$ & 0.2 & $0.03-2$ & 0.1 \\
\hline Respiratory disease (Y:N) & $14: 32$ & 13:109 & 3.6 & $1.5-8.5$ & 0.003 \\
\hline Lobectomy, bilobectomy vs. pneumonectomy & $40: 6$ & $105: 17$ & 1.1 & $0.39-2.9$ & 0.5 \\
\hline Muscle sparing vs. standard thoracotomy & $19: 27$ & $39: 83$ & 1.4 & $0.7-3$ & 0.1 \\
\hline Benign vs. malignant & $22: 24$ & $72: 50$ & 0.6 & $0.3-1.2$ & 0.1 \\
\hline Operating time $\mathrm{a}^{\mathrm{a}}, \mathrm{h}$ & $3.5(0.7)$ & $3.08(0.7)$ & - & $0.2-0.7$ & 0.6 \\
\hline Intraoperative blood loss ${ }^{\mathrm{a}}, \mathrm{ml}$ & $547.8(364.3)$ & $345.7(279.8)$ & - & $97.8-306.3$ & 0.001 \\
\hline Extended operation $(\mathrm{Y}: \mathrm{N})$ & $12: 34$ & $8: 114$ & 5 & $1.9-13.3$ & 0.001 \\
\hline
\end{tabular}

$\mathrm{OR}=$ Odds ratio; $\mathrm{CI}=$ confidence interval; $\mathrm{Y}=$ yes; $\mathrm{N}=$ no.

${ }^{\mathrm{a}}$ Mean (SD).

\section{Outcome}

Two deaths (mortality rate $1.1 \%$ ) occurred within 30 days after operation. Both patients had lung resection for malignancy. One patient died on day 7 due to massive pulmonary embolism and the other on day 21 due to respiratory failure. The mean duration of postoperative hospital stay was 9 days (7.8-12.6 days) and 12 days (1022 days) for patients without and with PPCs, respectively $(\mathrm{p}<0.004)$.

\section{Discussion}

The finding of $27 \%$ PPCs is within the reported range of $7-49 \%$ of published studies [1-3]. The variability between different series could be explained by the methodology used and type of surgery. Most published studies in the literature were retrospective and hence data collection might not have been as complete as in prospective studies. This prospective study can be considered as population-based because we included all consecutive patients undergoing major lung resection from 2002 to 2004 in the Chest Diseases Hospital, the only centre for the surgi-
Table 4. Multivariate analysis forward logistic regression

\begin{tabular}{lccl}
\hline Variable & OR & $95 \%$ CI & p value \\
\hline Comorbid cardiopulmonary disease & 0.2 & $0.1-0.5$ & 0.001 \\
Age $(<65$ years: $\geq 65$ years $)$ & 3.7 & $1.5-8.6$ & 0.002 \\
FVC $(<50 \%:>50 \%)$ & 0.2 & $0.1-0.8$ & 0.02 \\
Blood transfusion (Y:N) & 0.2 & $0.11-0.46$ & 0.0001 \\
Extended operation & 0.2 & $0.07-0.6$ & 0.005 \\
\hline
\end{tabular}

$\mathrm{OR}=$ Odds ratio; $\mathrm{CI}=$ confidence interval; $\mathrm{Y}=$ yes; $\mathrm{N}=$ no.

cal treatment of chest diseases in Kuwait. However, the drawback of this study is that the number is small and the population heterogeneous. The most frequent postoperative complication of this study $(15 \%)$ which was prolonged air leak lasting more than 7 days is consistent with previous studies [2, 4, 5]. This unavoidable complication, though not life-threatening, is a major factor in increasing the hospital stay and corresponding costs, as well as increasing the rate of postoperative morbidity such as empyema, pneumonia and fever [6]. Brunelli et al. [6] re- 
ported that for patients with reduced predicted postoperative FEV1, the presence of pleural adhesions and upper lobectomies is a predictive factor for prolonged air leak, whereas Abolhoda et al. [4] showed that FEV1/FVC of less than $50 \%$ was associated with prolonged air leak. In our study, two predictive independent risk factors for prolonged air leak were extended operation (OR 8.8, 95\% CI: 3.1-24.7, $\mathrm{p}=0.0001$ ) and patients with chronic obstructive airway disease (OR 3.8, 95\% CI: 1.3-11.2, p = $0.01)$. The prevention of air leak begins in the operating room by meticulous surgical techniques and complete expansion of the remaining lung. Postoperatively, ensuring full expansion and pleural apposition are essential if prolonged air leak is to be avoided.

The rate of $3 \%$ of bronchopleural fistula after pneumonectomy compares with the rates of $4-9 \%$ reported by other investigators $[2,7]$. It is the most serious postoperative complication, especially after pneumonectomy, and is usually associated with poor quality of life and a high mortality rate (29-79\%), as reported by Bernard et al. [7]. The preoperative predisposing factors for developing bronchopleural fistula are preoperative chemo- and/ or radiotherapy, benign infected disease, immunosuppressant, diabetes mellitus, and low FEV1 or DLCO [8]. Surgical risk factors include long residual stump, residual tumour at the bronchial margins, right pneumonectomy, devascularization of the bronchial stump, prolonged ventilation and reintubation [8].

Numerous risk factors have been reported for poor outcome after pulmonary resection such as age, type and extent of surgery, abnormal spirometry, male sex and comorbidity [1,7]. Age greater than $65-70$ years has been associated with an increased incidence of major complications but Abolhoda et al. [4] did not report any significant difference. The difference in these results may be due to the fact that different criteria were used to select patients undergoing lung resection or the extent of surgical resection varied in different series. In this study using univariate and multivariate analysis, an age older than 65 years was associated significantly with PPCs $(p=0.002)$. The incidence of postoperative complications and the mortality rates in patients who undergo lobectomies and bilobectomies are clearly lower than those associated with more extensive resection that include pneumonectomy, chest wall resection, pericardial and diaphragmatic resection $[7,9,10]$. In our series, extended resection was a risk factor for developing PPCs, while others have reported reduced FEV1 as a predictive risk factor for increased PPCs and death [1, 9-12]. Myrdal et al. [1] showed that low respiratory capacity assessed as FEV1 appears to be the most important predictor of a high risk of complications after lung resection. They showed that respiratory complications were closely related to impaired preoperative pulmonary function (FEV1 $<70 \%$ ) and were associated with approximately $50 \%$ of all deaths. In the present study, patients with FEV $1<1.3$ litres had $62.5 \%$ PPCs as compared to $24 \%$ for those with FEV1 $\geq 1.3$ litres. This result was statistically significant $(\mathrm{p}=0.002)$.

The association of pulmonary complications with the increased incidence of other morbidity factors in surgical procedures is well established particularly in relation to cardiac complications. Whether the cardiac event predisposes to the pulmonary event or vice versa is probably difficult to determine since the two frequently occur simultaneously $[13,14]$.

\section{Conclusion}

Pulmonary complications are mainly responsible for morbidity of patients undergoing major lung resection. These are likely to develop in patients with age $\geq 65$ years with comorbid cardiopulmonary disease, FVC $<50 \%$, blood transfusion, and extended operation. Great care must be taken to identify the patients who are at increased risk and determine methods to reduce morbidity and mortality. 


\section{References}

1 Myrdal G, Gustafsson G, Lambe M, Horte LG, Stahle E: Outcome after lung cancer surgery. Factors predicting early mortality and major morbidity. Eur J Cardiothorac Surg 2001;20: 694-699.

-2 Stephan F, Boucheseiche S, Hollande J, Flahault A, Cheffi A, Bazelly B, Bannet F: Pulmonary complications following lung resection. A comprehensive analysis of incidence and possible risk factors. Chest 2000;118:1263-1270.

$>3$ Licker M, de Perrot M, Hohn L, Tschopp JM, Robert J, Frey JG, Schweizer A, Spiliopoulos A: Perioperative mortality and major cardiopulmonary complications after lung surgery for non-small cell carcinoma. Eur J Cardiothorac Surg 1999;15:314-319.

4 Abolhoda A, Liu D, Brooks A, Burt M: Prolonged air leaks following radical upper lobectomy: an analysis of incidence and possible risk factors. Chest 1998;113:1507-1510.

$\checkmark 5$ Cerfolio RJ, Allen MS, Trastek VF, Deschamps C, Scanlon PD, Pairolero PC: Lung resection in patients with compromised pulmonary function. Ann Thorac Surg 1996;62:348-351.
66 Brunelli A, Al Refai M, Muti M, Sabbatini A, Fianchini A: Pleural tent after upper lobectomy: a prospective randomized study. Ann Thorac Surg 2000;69:1722-1724.

$>7$ Bernard A, Ferrand L, Hagry O, Benoit L, Cheynel N, Favre JP: Identification of prognostic factors determining risk groups for lung resection. Ann Thorac Surg 2000;70:11611167.

$>8$ Cerfolio RJ: The incidence of, etiology, and prevention of postresectional bronchopleural fistula. Semin Thorac Cardiovasc Surg 2001; 13:3-7.

$>9$ Duque JL, Ramos G, Castrodeza J, Cerezal J, Castanedo M, Yuste MG, Heras F: Early complications in surgical treatment of lung cancer: a prospective, multicenter study. Ann Thorac Surg 1997;63:944-950.

10 Ploeg AJ, Kappetein AP, van Tongeren RB, Pahlplatz PV, Kastelein GW, Breslau PJ: Factors associated with perioperative complications and long-term results after pulmonary resection for primary carcinoma of the lung. Eur J Cardiothorac Surg 2003;23:26-29.
11 Harpole DH, Liptay MJ, DeCamp MM, Mentzer SJ, Swanson SJ, Sugarbaker DJ: Prospective analysis of pneumonectomy: risk factors for major morbidity and cardiac dysrhythmias. Ann Thorac Surg 1996;61:977982

12 Wang J, Olak J, Ultmann RE, Ferguson MK: Assessment of pulmonary complications after lung resection. Ann Thorac Surg 1999;67: 1444-1447.

13 Busch E, Verazin G, Antkowiak JG, Driscoll D, Takita H: Pulmonary complications in patients undergoing thoracotomy for lung carcinoma. Chest 1994;105:760-766.

14 Licker M, Spiliopoulos A, Frey JG, Robert J, Hohn L, de Perrot M, Tschopp JM: Risk factors for early mortality and major complications following pneumonectomy for non-small cell carcinoma of the lung. Chest 2002;121: 1890-1897. 